\title{
A Case Study of the Effects of CO2-Induced Climatic Warming on Forest Growth and the Forest Sector : A. Productivity Reactions of Northern Boreal Forests.
}

Kauppi, P.E.

Kluwer

1988

Kauppi, P.E., Posch, M. 1988. A Case Study of the Effects of CO2-Induced Climatic Warming on Forest Growth and the Forest Sector: A. Productivity Reactions of Northern Boreal Forests. In: The Impact of Climatic Variations on Agriculture, Volume 1: Assessment in Cool Temperate and Cold Regions (Eds. Parry, M.L., Carter, T.R., and Konijn N.T.): 183-195.

http://hdl.handle.net/1975/9277

Downloaded from Helda, University of Helsinki institutional repository.

This is an electronic reprint of the original article.

This reprint may differ from the original in pagination and typographic detail.

Please cite the original version. 


\section{The Impact of}

Climatic Variations

on Agriculture

VOLUME 1: ASSESSMENT IN COOL

TEMPERATE AND COLD REGIONS

Edited by

M. L. Parry

T. R. Carter

Department of Geography, The University of Birmingham, U.K.

and IIASA, Vienna, Austria

and

\section{N. T. Konijn}

Department of Soil Science, Agricultural University,

Wageningen, The Netherlands

KLUWER ACADEMIC PUBLISHERS

DORDRECHT / BOSTON / LONDON

THE INTERNATIONAL INSTITUTE FOR APPLIED SYSTEMS ANALYSIS UNITED NATIONS ENVIRONMENT PROGRAM 
L ibrary of Congress Cataloging in Publication Data

The Impact of climatic variations on agriculture.

On v. 1 t.p.: The International Institute for

Applied Systems Analysis, United Nations Environment

Program.

Includes index.

Contents: v. 1. Assessments in cool temperate and cold regions.

1. Crops and climate. 2, Climatic changes.

3. Meteorology, Agricultural. I. Parry, M. L.

(Martin L.) Il. Carter, Timothy (Timothy R.)

II . Konijn, Nicolaas. IV. International Institute

for Applied Systems Analysis. V. United Nations

Environment Programme.

$5600.7 . C 54146 \quad 1988 \quad 630^{\prime} .2 * 516$

$88-3146$

ISBN 90-277-2700-7(v.1)

$1 S B \times 90-277-2701-5$ (v. 1 pbk.)

Published by Kluwer Academic Publishers,

P.O. Box 17,3300 AA Dordrecht, The Netherlands.

Kluwer Acudemic Publishers incorporates

the publishing programmes of

D. Reidel, Martinus Nijhofr, Dr W. Junk and MTP Presh.

Sold and distributed in the U.S.A. and Canada

by Kluwer Acaldemic Puhlishers,

101 Philip Drive, Norwell, MA 02061 , U.S.A.

In all other countries, sold and distributed

by Kluwer Academic Publishers Group.

P.O. Box 322. 3300 AH Dordrecht, The Netherlands.

All Rights Reserved

1988 by International Insitute for Applied Systems Analysis and United Nations Invironment

Program.

No part of the material protected by this copyright notice may be reproduced or

utilized in any form or by any means, electronic or mechanical

including photucopying, recording or by any information storage and

retrieval ystem, without written permission from the copyright owner. 


\section{A Case Study of the Effects of $\mathrm{CO}_{2}$-Induced Climatic Warming on Forest Growth and the Forest Sector: A. Productivity Reactions of Northern Boreal Forests}

Pekka Kauppi and Maximilian Posch

\subsection{Introduction}

The purpose of this section is to evaluate the effects of changes in climate under the GISS $2 \times \mathrm{CO}_{2}$ scenario (considered in Section 3) on the productivity of boreal forests. Some of the results reported here will be used as inputs to a further set of experiments concerned with the effect of productivity changes on forestry as an economic activity (see Section 6). Together Sections 5 and 6 provide a case study (at a hemispheric scalc) of the advantages and limitations of linking biophysical and economic models in attempts to assess the effects of climatic change.

\subsection{Temperature and the Productivity of Boreal Forests}

Cool climate - particularly in spring, summer and autumn - restricts the productivity of boreal forests. Low winter temperatures may not be so crucial, however, because plants are adapted to tolerate low temperatures in their dormant stage. Low productivity occurs partly because of a short growing season due to spring and autumn frosts which force plants to adapt by remaining dormant over a large part of the year. In addition, low growing season temperatures tend to restrict the rate of biological processes and in this way also to decrease productivity. It appears that the productivity of boreal ecosystems is rather closely 
correlated with the amount of heat accumulated during the year, as obtained by subtracting the plants' threshold temperature from the mean temperature of the day and summing up over the year. The value obtained is termed the annual effective temperature sum (ETS) measured in degree-day units.

Two essentially different factors, the magnitude of the warming and the potential of ecosystems to react to it, determine how ecosystems will respond to a possible climatic warming. Under the GISS $2 \times \mathrm{CO}_{2}$ climatic scenario the largest warming would take place in continental regions such as North America and continental Siberia. The GISS $2 \times \mathrm{CO}_{2}$ climatic scenario represents future averaged equilibrium climatic conditions, based on simulations by the Goddard Institute for Space Studies (GISS) general circulation model (GCM) for a doubling of the present concentrations of atmospheric carbon dioxide. (For details, see Section 3.) Smaller increases in temperature are estimated in maritime regions. Also, the potential of ecosystems to react to the warming can be assumed to vary in time and space. Within the boreal zone maritime ecosystems may conceivably be potentially more responsive (Kauppi and Posch, 1985). Continental ecosystems were estimated to be potentially less responsive. In this way, it appears that the two factors - climatic warming and ecological response tend to have regional distributions with opposite effects. However, in our earlier analysis, we did not examine which of the two factors would dominate. This study focuses on the possible long-term increase in the productivity of boreal forests and combines the estimated increase in temperature together with the potential of forests to react to this increase.

Before proceding with this, however, some important caveats are in order:

(1) Increased atmospheric $\mathrm{CO}_{2}$ concentrations can themselves cause enhanced photosynthetic activity (and hence net productivity) and also increase the water utilization efficiency of plants (Kramer, 1981; Kauppi, 1987).

(2) Changes in other climatic variables . such as precipitation, insolation and windspeed - are also likely to accompany $\mathrm{CO}_{2}$-induced temperature changes.

(3) Several other factors are important to tree growth, for example, the incidence and activity of pests and diseases, the rates of nutrient cycling and other processes in the soil and ground litter, and the susceptibility of trees to frost damage.

These factors, while important, are not considered in this study.

\subsection{Data and Study Procedure}

In line with experiments conducted in individual case study regions, this analysis is based on the GISS GCM-generated results for estimating temperature conditions for $1 \times \mathrm{CO}_{2}$ and $2 \times \mathrm{CO}_{2}$ environments (see Section 3). In order to generate a scenario for a climatic warming the $2 \times \mathrm{CO}_{2}$ results were compared with the $1 \times \mathrm{CO}_{2}$ results and to gridded observed data (source: Schutz and Gates - 
see References, Section 3) for describing the existing climate. All data used in this study are given on a grid covering the northern hemisphere between $28^{\circ} \mathrm{N}$ and $70^{\circ} \mathrm{N}$. The grid size is $5^{\circ}$ in an east-west and $4^{\circ}$ in a north-south direction; this gives a total of $9 \times 72=648$ data points.

Observed mean monthly temperature data were converted into ETS vialues for each grid point, applying a threshold temperature of $T_{0}=+5{ }^{\circ} \mathrm{C}$. Calculating ETS from the temperature time series would require data on daily observations, yet only monthly mean temperatures were available, and a method was developed for approximating ETS from these data. It was assumed that the daily temperatures are normally distributed around the monthly mean, $\bar{T}$. This assumption was tested statistically using Finnish data from 20 metcorological stations, 10 years and 12 months each year. For these data the assumption was found to be valid with only a few exceptions. The standard deviation $\sigma$ varied from $3.0^{\circ} \mathrm{C}$ to $5.5^{\circ} \mathrm{C}$ in winter and from $1.5^{\circ} \mathrm{C}$ to $4.0^{\circ} \mathrm{C}$ in summer. Therefore a value of $\sigma \quad 33^{\circ} \mathrm{C}$ was selected to describe that distribution, and on this basis the monthly E'TS was computed as follows ( $N$ is the number of days per month):

$$
\begin{aligned}
E T S- & \int_{T_{0}}^{\infty}\left(T-T_{0}\right)-\frac{N}{\sqrt{2 \pi} \sigma} \exp \left[\frac{\left(T \bar{T}^{\prime}\right)^{2}}{2 \sigma^{2}}\right] \mathrm{d} T \\
& \quad \sqrt{\sqrt[N]{2 \pi}} \exp \left[-\frac{\left(\bar{T}-T_{0}\right)^{2}}{2 \sigma^{2}}\right]+\frac{N}{2}\left(\bar{T} T_{0}\right)\left[1+\operatorname{erf}\left(\begin{array}{cc}
\bar{T} & T_{0} \\
-\sqrt{2} \sigma
\end{array}\right)\right]
\end{aligned}
$$

where

$$
\operatorname{erf}(x)=\frac{2}{\sqrt{\pi}} \int_{0}^{x} \mathrm{e}^{-t^{2}} \mathrm{~d} t
$$

Monthly ETS values were summed up to give the annual E'TS. Note that equation (5.1) is of an identical form to an equation used to compute ETS in an earlier paper (Kauppi and Posch, 1985). However, the integration in equation (5.1), in contrast to the earlier equation, applies to monthly (rather than annual) mean temperature and requires standard deviations of daily mean temperature around the monthly (rather than the annual) mean.

E'S was calculated in the same way for a climatic scenario referring to doubled $\mathrm{CO}_{2}$ conditions (assuming the same standard deviation). The scenario was constructed using GISS model results by first subtracting the computed $1 \times$ $\mathrm{CO}_{2}$ (reference) temperature from the computed $2 \times \mathrm{CO}_{2}$ temperature for each grid point. The difference was added to the Schutz and Gates observed temperature at each grid point to correct for errors in the modeled reference level. Scenario estimates for mean monthly temperatures (and thus, of course, for ETS) were higher than the corresponding reference temperatures at all grid points. 

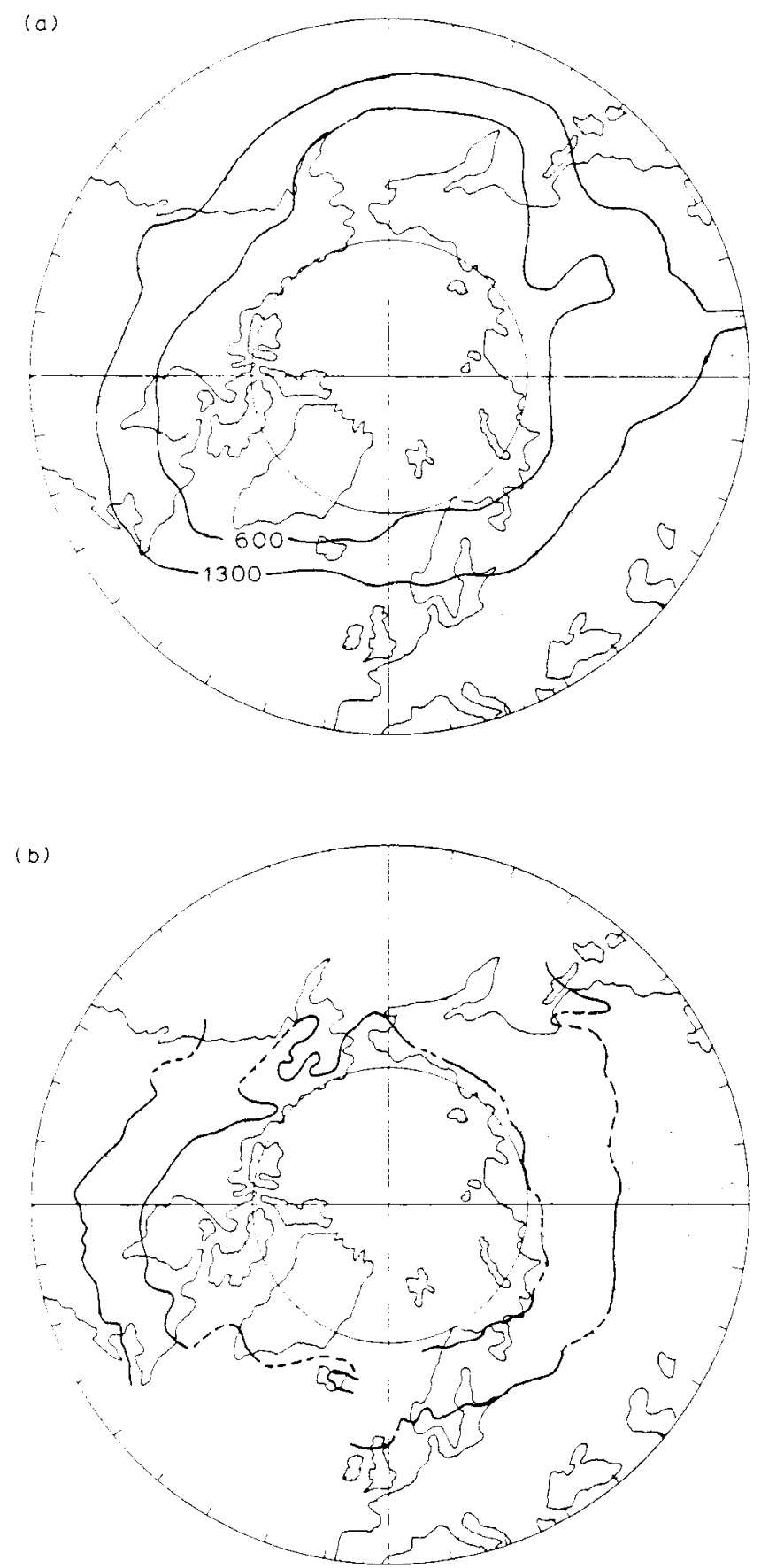

Figure 5.1. (a) Calculated boreal zone: the band between ETS isopleths of 600 and 1300 degree-days. (b) Observed boreal zone, redrawn from Hämet-Ahti (1981). 


\subsection{Locating Regions with a High ETS Response}

To test whether or not the annual ETS concept is applicable for describing the boundaries of the boreal zone, isopleths of ETS were compared with the vegetation map compiled by llämet- $\Lambda$ hti (1981). Based on the situation in the Fennoscandian peninsula, FTS isopleths of 600 and 1300 degree-days were used to describe the northern and southern boundaries of the zone. These calculated boundaries were compared with those observed (Figure 5.1). In the Fennoscandian peninsula the values 600 and 1300 degree-days quite accurately bound the central parts of the biome, i.e., the northern boreal, middle boreal and southern boreal subzones as classified by llämet- $\Lambda$ hti (1981). However, in certain areas of the Pacific region the calculated and observed locations of the zone tend to depart. The calculated northern boundary fails to include some parts of the boreal biome in Alaska and Kamchatka. The match is again quite reasonable from British Columbia castwards to the Atlantic Occan and further east towards western Siberia, that is, over at least two-thirds of the zone.

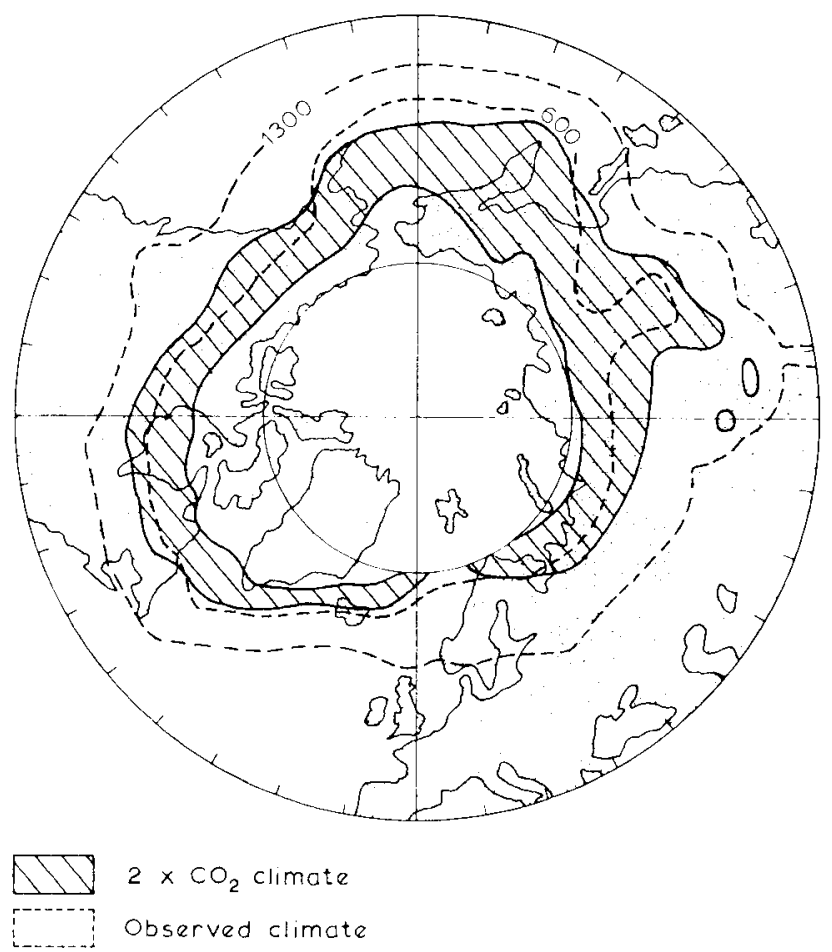

Figure 5.2. Calculated boreal zone for the GISS $2 \times \mathrm{CO}_{2}$ climate scenario relative to the calculated present-day zone [from Figure 5.1(a)]. 

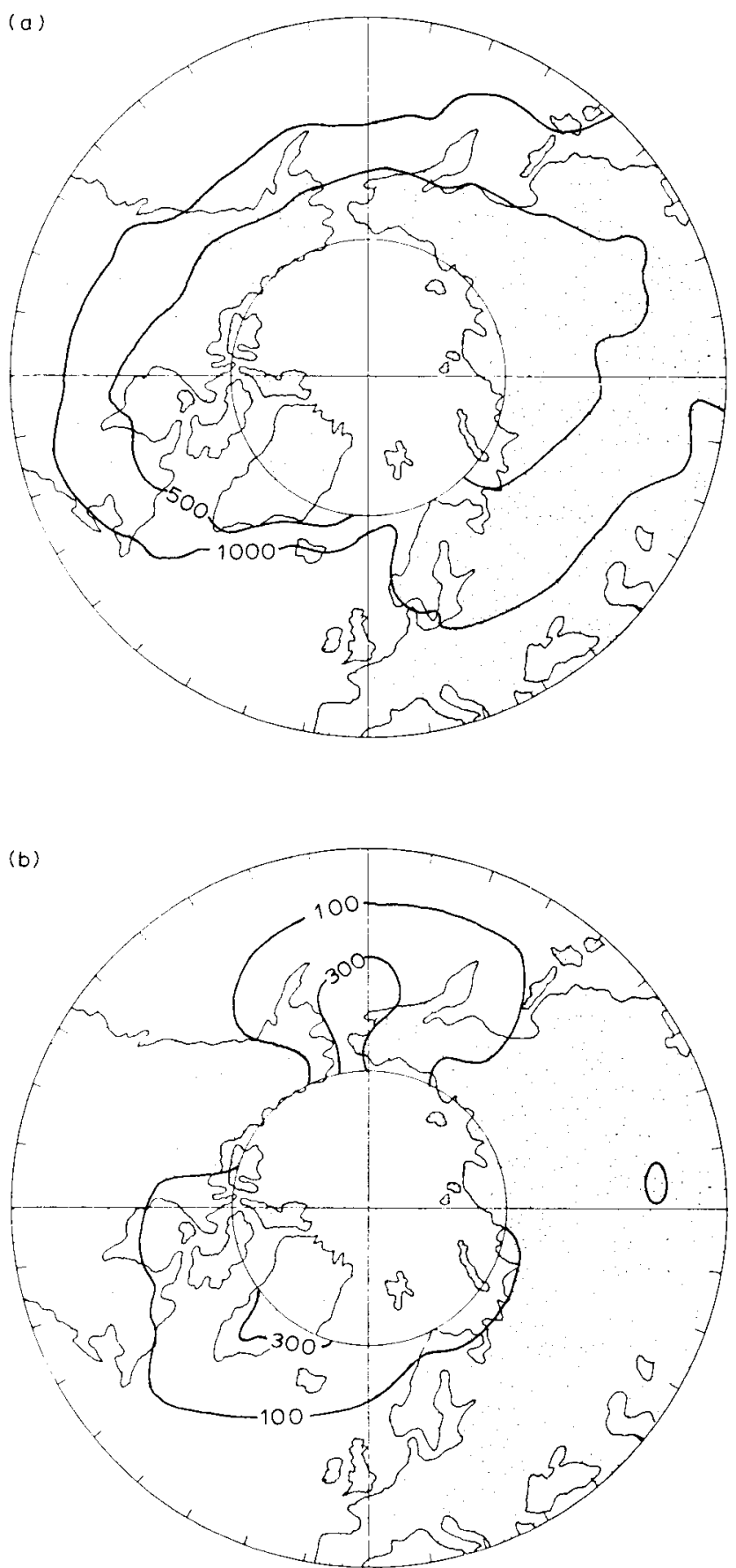

Figure 5.3. Estimated change of ETS for the GISS $2 \times \mathrm{CO}_{2}$ climate scenario (a) in absolute units (degree-days), $(b)$ in relative units with isopleths indicating doubling (100\% increase) and quadrupling (300\% increase) of ETS. 
One must bear in mind that the two sets of data are not fully independent. The region is so large that the vegetation map has been constructed not only on the basis of botanical field observations but also using supplementary temperature data (similar to those used in estimating the calculated zone) as a proxy for botanical information.

The 600 and 1300 degree-days ETS boundaries were calculated in the same way for the GISS $2 \times \mathrm{CO}_{2}$ scenario. According to this scenario the zone would shift northwards by $5001000 \mathrm{~km}$ (Figure 5.2). Emanuel et al. (1985a) reported even larger estimates for such shifts based on a different climate model, namely that of Manabe and Stouffer (1980) and the Holdridge classification of vegetation zones; although in response to criticisms of their methods (Rowntree, 1985) these estimates have since been revised downwards (Emanuel et al., 1985b).

A comparison was made between the estimated FTS for the doubled $\mathrm{CO}_{2}$ scenario $E T S_{2}$ and that representing the observed climate using the Schutz and Gates temperature data $E T S_{0}$. The increase of ETS was calculated in absolute units, $E T S_{2}-E T S_{0}$, as well as in relative units, $100\left(E T S_{2} E T S_{0}\right) / E T S_{0}$. 'The relative increase indicates how dramatic the change would be in relation the historical reference level. An interesting finding was that highest increases. at a given latitude, were estimated over maritime regions. This result was obtained with both indicator variables, that is, both in absolute and in relative units (Figure 5.8).

\subsection{Possible Growth Response}

Effective temperature sum is a variable which has been applied in the boreal zone both in agriculture and in forestry investigations. It has relevance especially in the northern part of the zone where soil moisture is almost always sufficient even to the extent that excess water and the subsequent peat formation frequently limit forest productivity (Mikola, 1950). Significant moisture deficiency appears only towards the southern part of the zone. Were drought, may limit agricultural crop yields and, hence, the ETS variable is only weakly correlated to agricultural crop yield (Mukula et al., 1978; see Part IV). The ETS variable alone is not particularly useful in studies which focus on any specific ecosystem, but it may have some value in rough regional comparisons. Therefore, for demonstrative purposes, we convert the FiTS results to estimates of potential forest productivity.

Average tree growth varies in Finland from $1.2 \mathrm{~m}^{3} \mathrm{ha}{ }^{11} \mathrm{yr}{ }^{1}$ in northerm regions to $5.0 \mathrm{~m}^{3} \mathrm{ha}^{-1} \mathrm{yr}^{-1}$ in southern regions and is rather closely correlated with ETS (Figure 5.4). Each data point in Figure 5.4 represents one "Forestry Board" district. The size of the districts varies from $4000-51000 \mathrm{~km}^{2}$. EJS data were average values for the period 1931-1960, and the growth data were inventory results from 1951 1953. The inventory was based on a random sample from all forests, and in this way the data represent the average case rather than the conditions of any specific ecosystem. The national forest inventory has been repeated seven times between 1920 and 1980 . The regional pattern of tree growth as measured in the third inventory $(1951 \% 1953)$ is representative for the 


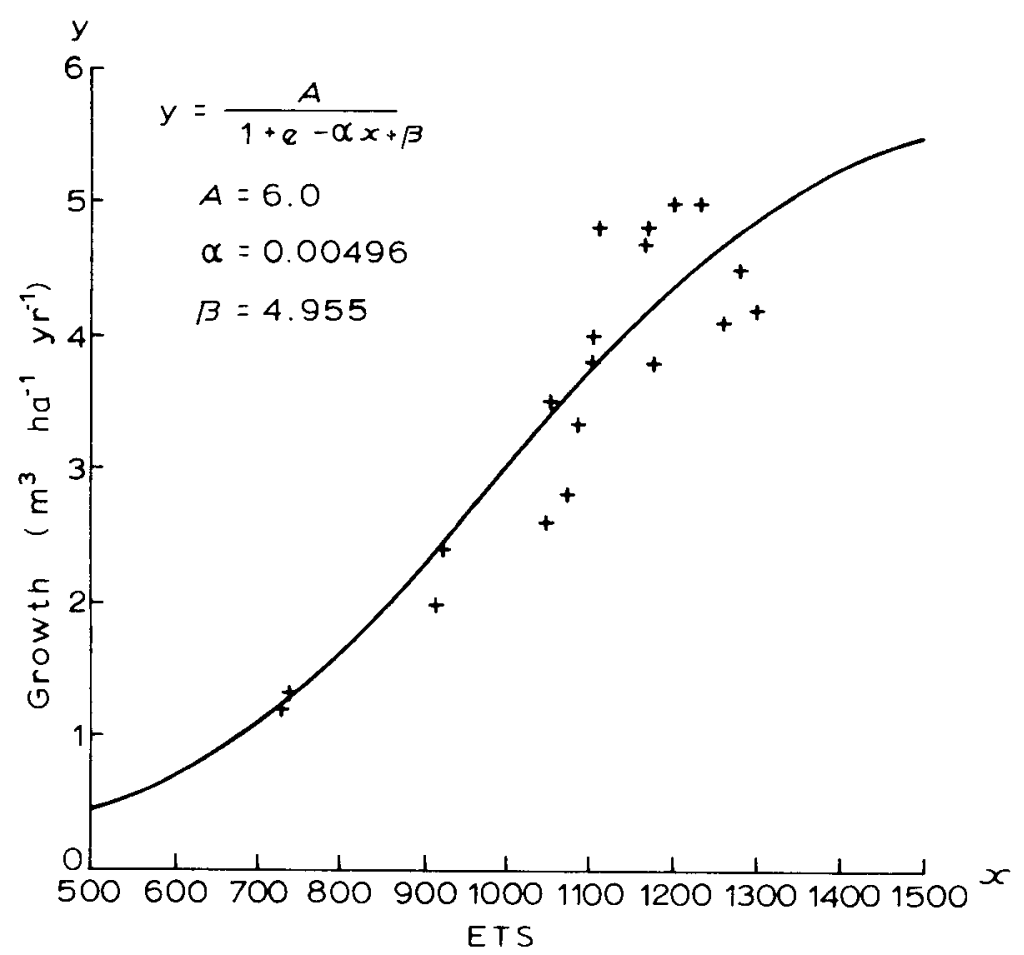

Figure 5.4. Empirical relationship between annual effective temperature sum (F'TS) and annual mean tree growth.

whole 60-year period (Yearbook of Forest Statistics, 1983). Finnish forests are managed for timber production and are low-land forests with relatively sheltered exposures, their growth figures being generally higher than those of forests elsewhere in the boreal zone. Thus conditions for growth that pertain to Finnish conditions, if applied to other parts of the boreal zone, tend slightly to overestimate productivity in that zone (as discussed in Section 6 ).

The relation between ETS (denoted as $x$ ) and tree growth $(y)$ was assumed to be adequately represented by a logistic function:

$$
y=\frac{A}{1+\mathrm{e}^{-\alpha x+\beta}}
$$

where $A$ is the maximum growth rate (assumed $=6.0 \mathrm{~m}^{3} \mathrm{ha}^{-1} \mathrm{yr}^{-1}$ ), and $\alpha$ and $\beta$ are coefficients (0.00496 and 4.955 , respectively).

Data from Finland were used to determine the parameters of the function (see Figure 5.4). The leveling-off of the function for high ETS values takes into account the drought limitation of growth in high ETS conditions. This functional relationship between ETS and growth was used to map productivity 

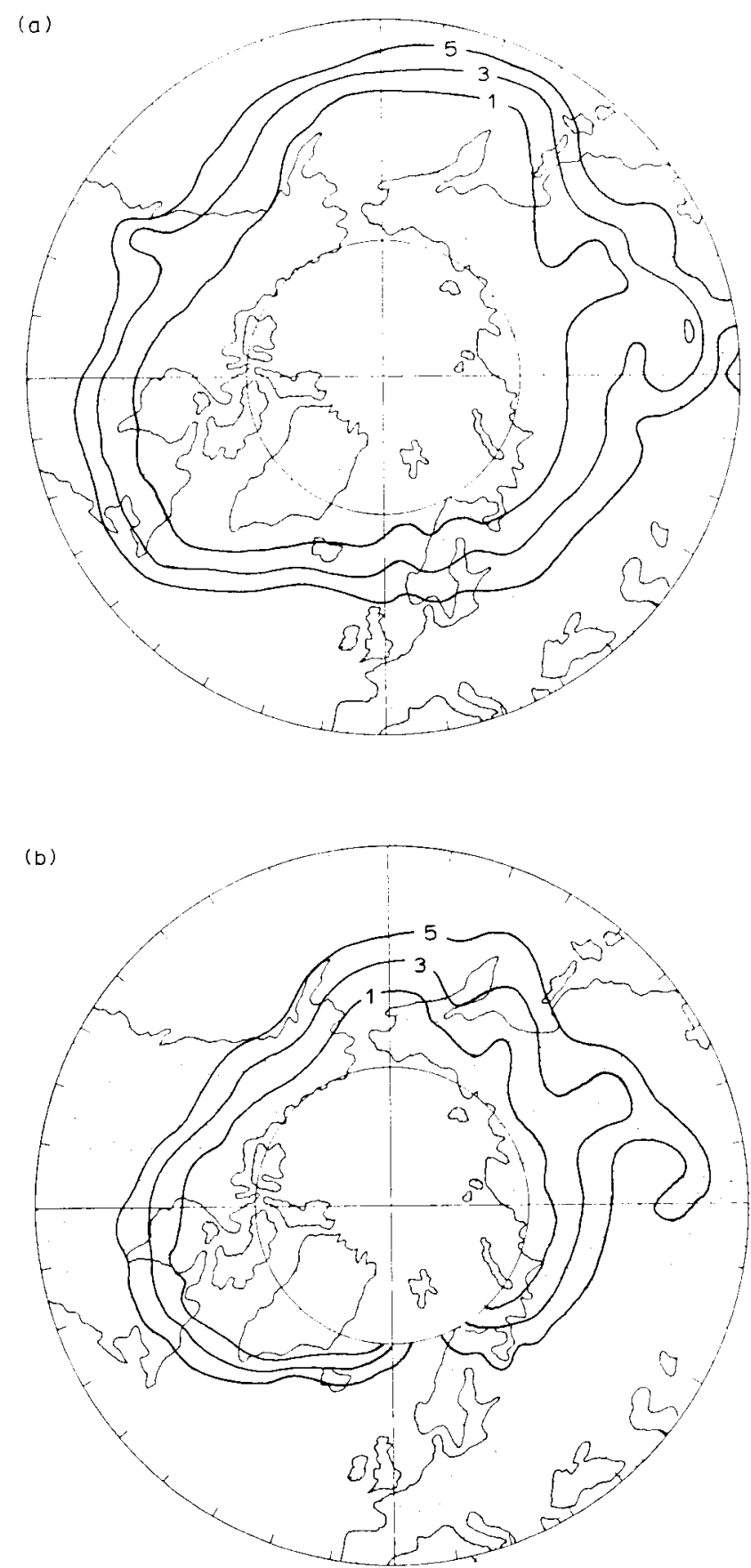

Figure 5.5. Estimated productivity regions of boreal forests (a) for observed (Schutz and Gates) climatic data, (b) for the GISS $2 \times \mathrm{CO}_{2}$ climate scenario. Values refer to the regional average of potential stemwood productivity in $\mathrm{m}^{3} \mathrm{ha}^{-1} \mathrm{yr}^{-1}$. 


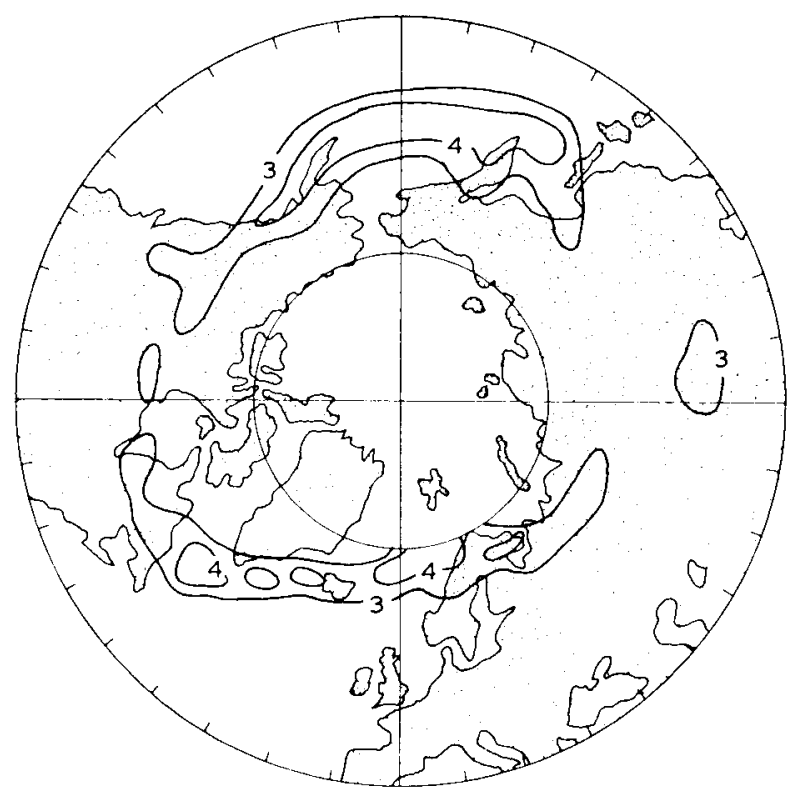

Figure 5.6. Estimated change in potential productivity from baseline level to doubled $\mathrm{CO}_{2}$ conditions (in $\mathrm{m}^{3} \mathrm{ha}^{-1} \mathrm{yr}^{-1}$ ).

regions for the observed climate $\{$ Figure $5.5(a)\}$ and for the GISS $2 \times \mathrm{CO}_{2}$ climate [Figure 5.5(b)].

The changes of growth from observed climate to doubled $\mathrm{CO}_{2}$ climate were estimated in absolute units $\left(\mathrm{m}^{3} \mathrm{ha}^{-1} \mathrm{yr}^{-1}\right)$. The greatest growth changes were estimated in maritime regions in the northern parts of the observed zone (Figure 5.6). Several factors affect this result. In the northernmost regions even the doubled $\mathrm{CO}_{2}$ climate was estimated to be too cold to maintain any major productivity. In southern regions observed climate is currently rather favorable, but under doubled $\mathrm{CO}_{2}$ conditions it was assumed that moisture stress would restrict growth (leveling-off in Figure 5.4). During the winter period, with temperatures below the threshold, ecosystems are viewed as being dormant and ETS, by definition, does not respond to temperature variations. So, while ETS does not respond at all to a large rise in winter temperature from, say, $-40^{\circ} \mathrm{C}$ to $-15^{\circ} \mathrm{C}$, in contrast it responds rather strongly to a modest temperature rise from, say, $+3^{\circ} \mathrm{C}$ to $+7{ }^{\circ} \mathrm{C}$. Such temperatures (around the threshold temperature) occur quite frequently in maritime regions within the boreal zone, and this is the reason why the response is estimated to be higher in these regions.

An earlier hypothesis, mentioned above, stated that maritime areas of the boreal zone would be particularly susceptible to impacts from a possible climatic change (Kauppi and Posch, 1985). This new result suggests that despite the 
counteracting effect of relatively lower estimated climatic warming over maritime regions, maritime ecosystems might nevertheless respond more strongly than continental ecosystems. Highest responses were estimated in Labrador, southern Greenland, Iceland, northern Fennoscandia and around the Bering Strait (see Figure 5.6).

\subsection{Discussion}

If, indeed, the greenhouse effect of $\mathrm{CO}_{2}$ changed the climate as much as is supposed above, quite substantial changes could be expected between the boreal biome and the neighboring biomes - tundra to the north and the temperate zone to the south. It is almost impossible to assess which ecological, social or economic consequences would have the greatest impact. In this section, however, we have tried to specify regions within the borcal forest zone which would respond more strongly than others from the standpoint of productivity. This has been done by using rather simple indicator variables: effective temperature sum and forest productivity. The largest increase in growth is estimated to occur in maritime regions of the northern parts of the biome.

Several different sources of uncertainty in this kind of analysis have emerged from the study. First of all there is uncertainty associated with the input data. Observed climate, for example, necessarily contains approximations because the area is very large and it is only partially covered by sufficicntly dense networks of meteorological stations. Further uncertainties are associated with the modeling of climatic changes due to doubled $\mathrm{CO}_{2}$ conditions, related both to the simplifying assumptions and inaccuracies of the climate model itself and to the omission in the analysis of changes in other climatic variables such as precipitation and evapotranspiration, although these would perhaps have fewer consequences in the boreal zone than elsewhere in the world. Moreover, while it is reasonably clear that atmospheric $\mathrm{CO}_{2}$ concentrations will continue to increase in the next few decades even if the anthropogenic sources were "switched off" immediately (due to the ocean inertia effect - see Section 3), it is not certain that $\mathrm{CO}_{2}$ concentrations will ever grow to values twice as high as the reference level.

Our method of calculating ETS is an approximation, especially the assumption that daily temperatures are distributed normally around the monthly mean, which has to be checked. A comparison of the results by assuming different distributions (including the rather unlikely case of an uniform distribution around the monthly mean) showed, however, that ETS values are rather insensitive to the particular shape of the distribution as long as they are unimodal. We also compared our method with the widely used formula $E T S=N\left(\bar{T}-T_{0}\right)$ for $\bar{T}>$ $T_{0}$, and here we found a deviation in the ETS of 30-40 degree-days per month for $\bar{T} \simeq T_{0}$. That simple formula is equivalent to assuming that the daily temperature is equal to the monthly mean, a rather rough.approximation we tried to overcome by using our formula.

A basic assumption of the calculations is that boreal forests are in equilibrium both with the present and with the $2 \times \mathrm{CO}_{2}$ climate. The approach is 
valid in the long run assuming that the atmospheric concentrations of $\mathrm{CO}_{2}$ and other greenhouse gases will stabilize at a new, relatively constant level. Time will be needed after such a stabilization for the climate to reach a new equilibrium (see, for example, llansen et al., 1985) and for the forests to become adapted to the new climate. The above results thus refer to the possible conditions in the future when essentially all equilibria have been reached.

If the rate of a climatic change is low, forests can change smoothly; first due to the phenotypic acclimatization, and then due to genetic adaptation. The latter process is rather slow in forests, where individual trees live 100-200 years and where the minimum time period between two successive generations is roughly 30 years. In this time perspective the observed and expected rates of the increase of the atmospheric $\mathrm{CO}_{2}$ concentration are rather high. One would not anticipate a smooth ecological transition unless the climatic response times are very long. In case of a rapid climatic change, forests would be susceptible to, for example, pests or extreme climatic events. In addition, as mentioned carlier, it is necessary to consider the so-called fertilizing effect of increased atmospheric $\mathrm{CO}_{2}$ on photosynthesis and plant growth, a matter which is outside the scope of this section (see Shugart et al., 1986). At the present state of knowledge it is very difficult to assess what actually would happen during such an obviously quite troublesome transition period. Nonetheless, with these caveats in mind, Section 6 considers some of the economic implications of possible changes in forest productivity.

\section{References}

Emanuel, W.R., Shugart, H.H. and Stevenson, M.P. (1985a). Climatic change and the broad-scale distribution of terrestrial ecosystem complexes. Climatic Change, 7 , 29-43.

Emanuel, W.R., Shugart, H.H. and Stevenson, M.P. (1985b). Response to comment: climate change and the broad-scale distribution of terrestrial ecosystem complexes. Climatic Change, 7, 457-460.

Hämet-Ahti, L. (1981). The boreal zone and its subdivision. Fennia, 159, 69-75.

Hansen, J., Russell, G., Lacis, A., Fung, I., Rind, D. and Stone, P. (1985). Climate response times: Dependence on climate sensitivity and ocean mixing. Science, 229, 857-859.

Kauppi, P. (1987). Forests and the changing chemical composition of the atmosphere. In M. Kallio, D.P. Dykstra and C.S. Binkley (eds.), The Global Forest Sector: An Analytical Perspective. J. Wiley and Sons, Chichester.

Kauppi, P. and Posch, M. (1985). Sensitivity of boreal forests to possible climatic warming. Climatic Change, 7, 45-54.

Kramer, P.J. (1981). Carbon dioxide concentration, photosynthesis and dry matter production. Bioscience, 31, 29-33.

Manabe, S. and Stouffer, R.J. (1980). Sensitivity of a global climate model to an increase of $\mathrm{CO}_{2}$ concentration in the atmosphere. J. Geophys. Res., 85, 5529-5554.

Mikola, P. (1950). On variations in tree growth and their significance to growth studies. Commun. Inst. For. Fenn., 38, 5. 
Mukula, J., Rantanen, O. and Lallukka, U. (1978). Crop certainty of oats in Finland 1950-1976. Report Nr. 10, Finnish Agricultural Research Center, Department of Plant Ilusbandry, Jokioinen (in Finnish).

Rowntree, P.R. (1985). Comment on "Climatic change and the broad-scale distribution of terrestrial ecosystem complexes" by Fmanuel, Shugart and Stevenson. Climatic Change, 7, 455-456.

Shugart, H.H., Antonovsky, M. Ya., Jarvis, P.G. and Sandford, A.P. (1986). CO, climatic change and forest ecosystems. Assessing the response of global forests to the direct, effects of increasing $\mathrm{CO}_{2}$ and climatic change. In B. Bolin, B.R. Dö̈s, J. Jäger and R.A. Warrick (eds.), The Greenhouse Effect, Climatic Change and Ecosystem.s, SCOPE 29, Wiley, Chichester, pp. $475-521$.

Yearbook of Forest Statistics (1983). Official Statistics of Finland, Vol. XVIIA, No.14, Folia Forestalia 550. 